\title{
ENEGRECER, SABOTAR A MEMÓRIA
}

\author{
Blacken, sabotage memory
}

Edélcio Mostaço

Universidade do Estado de Santa Catarina - UDESC

Resumo: O artigo trata do espetáculo Preto, estreado pela companhia brasileira de teatro em 2018. Partindo da fala da atriz negra Grace Passô, ele articula, através de uma construção performática, rizomas, acontecimentos e novos agenciamentos sobre a memória do racismo no Brasil. Sua construção en abyme subverte a percepção tradicional do tempo histórico, introduzindo a tensão deleuziana entre o virtual e o real.

Palavras-chave: Preto; Grace Passô; Márcio Abreu.

Abstract: This article deals with the show Preto (Black), premiered by the brazilian theater company in 2018. Starting from the speech of black actress Grace Passô, it articulates, through a performative construction, rhizomes, events and new assemblages about the memory of racism in Brazil. Its construction en abyme subverts the traditional perception of historical time, introducing the Deleuzian tension between the virtual and the real.

Keywords: Preto; Grace Passô; Márcio Abreu. 
Estreado em 2018, o espetáculo Preto constitui-se em uma avançada produção estética da Cia. brasileira de teatro, coletivo curitibano sob a direção de Márcio Abreu'. Desenvolvida em regime de pesquisa e aproveitando os inúmeros workshops promovidos com e sem a presença de público que seu tema central propiciou, a encenação é centrada sobre a atriz Grace Passô. A partir de uma fala solitária, pouco a pouco, novos planos são desdobrados em cena, procedimento que se revela ser não apenas o tema como a própria estrutura estética da realização, construída a partir de uma poética que, desrealizando os planos enunciativos entrecruzados, recorre aos híbridos, aos miscigenados, aos desdobramentos metafóricos para materializar uma polifonia de discursos.

Através dessas interfaces entre sua condição de mulher - negra, lésbica, feminista - e os vários vínculos que a interconexão dessas condições existenciais são capazes de ensejar, Preto alcança também uma dimensão decolonial, sugerindo e repensando nossa condição enquanto Nação.

\section{Platôs e rizomas}

A atriz Grace Passô, de pequena estatura, entra em cena e senta-se de costas para a plateia. Através de um microfone, ela cumprimenta e brinca um pouco com o público, antes de começar sua "conferência de uma mulher negra", observada da plateia, através de sua imagem projetada em uma grande tela ao fundo. Em seu discurso, a frase de maior impacto é: "o que fazer para que o enegrecimento seja cada vez maior, seja cada vez mais potente, no lugar onde estamos?".

Essa pergunta essencial, no Brasil de hoje, abre uma fissura. País colônia de Portugal, somente tornou-se independente em 1822 e somente libertou seus escravos em 1888, uma concessão efetivada pela supremacia da pequena população branca de origem europeia que controlava o país. Lançados à própria sorte, sem nenhum amparo, milhares de indivíduos pretos viram-se, de um dia

\footnotetext{
${ }^{1}$ No elenco, estavam: Cássia Damasceno, Felipe Santos, Grace Passô, Nadja Naira, Renata Sorrah e Rodrigo Bolzan. Música ao vivo por Felipe Storino. Dramaturgia de Grace Passô, Márcio Abreu e Nadja Naira.
} 
para o outro, sem casa, sem trabalho, sem condições de sobrevivência. Grace Passô é uma descendente de escravos e, desse modo, sua conferência, que tem como objetivo fazer com que o enegrecimento seja cada vez mais intenso, salta de sua cadeira e com sua voz convoca o fogo, uma vez que a chama incita, arde, chama a atenção, uma luz que também serve para indicar rotas de fuga, caso você estiver perdido em uma floresta.

A imagem de uma orelha projetada inicia o segundo platô de Preto, o da escuta do som ao redor. Uma mulher branca, chamada Renata, e um homem adentram o espaço cênico, e o diálogo entre eles sugere que se trata de uma entrevista, na qual ela é convocada a dar respostas sobre sua vida. Ela afirma que sempre falou o que pensa, que não se preocupa com sua imagem, que foi uma adolescente problemática e que não gosta de tirar fotos. Começam aqui a se mesclarem, quase sub-repticiamente, vários planos da tessitura narrativa do espetáculo: ele é uma grande metáfora, recorrendo às imagens - sua estrutura multimídia - para inserir novos rizomas de sentidos àquilo que parecia o depoimento de uma pessoa. Também a atriz branca é atormentada pelas imagens, embora por razões bem diversas.

A cena seguinte desborda todas as probabilidades. As duas atrizes, agora lado a lado e num cada vez mais estreito abraço, falam de afetos, de desejos, de ânsia sexual e volúpia, sem que se saiba se falam de si, de outras, de possibilidades ou fatos ocorridos, apenas um ritornelo atemporal que sugere ser uma das labaredas daquele fogo evocado ao início. Para enegrecer o aqui e agora, Preto não recusa nada, em busca de seu gozo total. Esse diálogo entre as atrizes passa, repentinamente, para outro rizoma, o delas mesmas falando sobre si próprias. Com essa nova brotação, o espetáculo reintroduz o atual em cena, outro desvio que recorda a imagem-movimento evocada por Gilles Deleuze, um cinema involuntário que a plateia é capaz de efetivar quando a imaginação se torna puramente óptica e sonora:

a imagem atual, cortada de seu prolongamento motor, entra em relação com a imagem virtual, imagem mental ou em espelho. Vi a fábrica, pensei estar vendo condenados... Ao invés de um 
prolongamento linear, tem-se um circuito em que as duas imagens não param de correr uma atrás da outra, em um ponto de indistinção entre o real e o imaginário. (DELEUZE, 2013, p. 71)

Obra híbrida, fragmentária e en abyme, Preto está em busca de uma antiga revolução, "uma tentativa de diálogo, de escuta, de afetar-se com a consciência da outridade", conforme explicita Grace Passô (2019, p. 9), no prefácio ao texto publicado. Tomando o lugar de fala de uma mulher negra lésbica, que vive o avesso do avesso do mundo branco que a cerca, por que o espetáculo então não se intitula Preta? Porque não é pessoal, não é subjetivo, não almeja ser autobiografia ou reduzir uma existência humana unicamente a si mesma. Preto é uma fala diaspórica, a partir de um lugar distópico - como um buraco negro que tudo abduz - capaz de tudo triturar em sua recusa ao algoritmo ocidental, um território de eventos de consciência que tenta escapar às determinações tempoespaciais.

Por isso efetiva, por intermédio de uma cena emblemática, uma breve rememoração de As Lágrimas Amargas de Petra von Kant, criação de Fassbinder, encenada no Brasil em 1982, e na qual Renata, a atriz branca aqui presente em cena, desempenhou o papel de Karin. Nessa evocação, Grace Passô faz Petra, invertendo a ordem dos discursos, enquanto uma terceira performer faz Marlene, a criada muda que tudo assiste em silêncio - como a escrava branca de uma estilista de sucesso - aos jogos de sedução entre as duas mulheres. A ligação entre essa e a sequência cênica inicial ocorre através de um copo de água que, desde o início, se encontrava em cima da mesa que Grace manipulara em sua conferência. Entre uma cena e outra, temos o clarão de um tempo não pulsado, um puro acontecimento, uma vez que somos arrastados pela presença de uma multiplicidade de durações heteróclitas, antes e agora, não coincidentes, exato contrário de um teatro simplesmente épico. A propósito desse expediente construtivo organizado por Márcio Abreu, Deleuze oferece uma explicação exemplar: "a lembrança coexiste com aquilo de que ela é lembrança, 
coexiste com a percepção correspondente; o presente é tão somente o grau mais contraído da memória, é um passado imediato" (DELEUZE, 1999, p. 119).

\section{Potência}

Assim como a narradora Grace, somos todos atravessados por forças explicitadas por Nietzsche como ativas e reativas, em sua obra $A$ Genealogia da Moral. É por esse viés que a ética, consubstanciada nos pequenos e nos grandes gestos materializados através das condutas, adentra o cotidiano e marca com seu selo as escolhas sobre ele efetivadas. Nascido das relações de compra e venda, nos primórdios das relações humanas, o sentimento de culpa foi se construindo desde os alicerces da humanidade:

comprar e vender, juntamente com seu aparato psicológico, são mais velhos inclusive do que os começos de qualquer forma de organização social ou de aliança: foi apenas a partir da forma mais rudimentar de direito pessoal que o germinante sentimento de troca, contrato, débito, direito, obrigação, compensação, foi transposto para os mais toscos e incipientes complexos sociais (em sua relação com complexos semelhantes), simultaneamente ao hábito de comparar, medir, calcular um poder e outro. (NIETZSCHE, II, 8, 1987, p. 73)

Tal perspectiva ajuda a aquilatar sua expressão contemporânea, magnificada pelo capital - cada coisa tem seu preço, tudo pode ser pago conforme destaca o autor de Assim Falou Zaratustra, raiz da dissimetria estrutural que domina as relações entre muitos povos do planeta.

"O que define um corpo é a relação entre forças dominantes e forças dominadas. Toda relação de forças constitui um corpo: químico, biológico, social, político", situa Gilles Deleuze (2018, p. 56), ao explicitar como tais forças constituem sempre um feixe de tensões resultantes das relações intersubjetivas, criando uma hierarquia entre os indivíduos, promovendo exclusões e subalternidades, uma vez que as forças ativas são as dominantes e as reativas as dominadas. 
Ao iniciar sua conferência, Grace Passô apela para sua vontade de potência: "eu vou falar a partir daí. Do preto. Da pretura. Da síncope. Da vertigem. Do fogo" (PASSÔ, 2019, p. 24). Temos, portanto, uma inversão de forças, a propulsão de um desejo, uma faísca no horizonte, fazendo com que o que era reativo se torne ativo, com que o biopoder encontre seu desabrochar enquanto revolta e grito contra uma condição historicamente subalternizada - necropolítica, dirá Achile Mbembe - ao situar como a carne negra é a mais barata do mercado.

A partir de seu terceiro movimento, após a rememoração organizada em torno de As Lágrimas Amargas de Petra von Kant, o espetáculo Preto envereda pela recordação, pela memória. Trata-se de história, mas não de historicismo, uma vez que não segue a cronologia causal, a síntese dos eventos, as relações dialéticas entre seres temporais, mas que vigora, enquanto articulação alegórica, em outra camada de signos, outra camada de intensidades, outra pulsão de imaginário: a matriz metropolitana europeia incrustrada na elite branca colonial, transposta sobre o escravismo africano de que somos uma parte. Uma parte estrutural, um dispositivo de poder, cujas representações sociais não seguem os padrões da ficção espetacular, mas aqueles dos recalques inconscientes.

"Quando a mulher negra se movimenta, toda a estrutura da sociedade se movimenta com ela, porque tudo é desestabilizado a partir da base da pirâmide social onde se encontram as mulheres negras, muda-se a base do capitalismo", declarou Ângela Davis na Bahia, em sua visita em 2017 (PASSÔ, 2019, p. 13). Essa proposição da feminista norte-americana foi uma das molas propulsoras para a construção do espetáculo Preto. Assim, partindo da memória de uma mulher negra, mas não a ela limitada ou à sua pessoa, a encenação abre espaço para outras performances, outros atos performativos que se desprendem desse território chamado Brasil. Atravessado, nos últimos anos, por aguda onda de misoginia, racismo e homofobia, crimes contínuos contra os direitos humanos da maior parte de sua população - de origem afrodescendente. Males que acompanham, como seu corolário, a rápida implantação de um capitalismo neoliberal voraz e predatório, responsável por três enormes desastres ambientais próximos a nós, poluindo com seus dejetos a terra e as águas em que nossos 
descendentes não poderão mais plantar ou pescar. Por isso, tudo é preto, tudo é buraco negro, tudo é mais rápido que a luz e tudo exige o enegrecimento.

Sobre a narrativa en abyme de Preto, pode-se ainda afirmar que um ser humano é formado bem mais pelos seus hábitos do que suas autodeterminações, como ainda uma vez nos explica Deleuze (1999), configurando um campo mental, no qual o presente vivo contrai o passado e antecipa o futuro. Um campo que é vivido enquanto duração, onde o passado não segue o presente e o presente não precisa se efetuar para se constituir em passado, pois ambos se atualizam todo 0 tempo. De modo que os hábitos, enquanto lembranças, se renovam a cada vez que são convocados, quando a memória se torna multiplicidade contínua, em diferentes graus de contração e distensão, multiplicidade de lembranças e perceptos coexistentes, vários passados e o presente existindo e se produzindo simultaneamente.

É por esse viés que a narrativa de Preto torna a memória virtual: através dos perceptos e afectos que é capaz de conclamar, de fazer eclodir, de dar voz e solidez no presente. E razão também pela qual a memória não se restringe à versão linear sobre os fatos, mas articula um caráter múltiplo e difuso, que se ramifica e se desdobra em modo magmático, a partir de uma cascata de planos temporais não solidários entre si. Uma memória não tópica, uma memória se fazendo no ato mesmo em que se atualiza.

\section{O trauma}

A partir de 2013, o Brasil entrou em um redemoinho, fazendo precipitar em um buraco negro processos históricos e conquistas sociopolíticas tidas e havidas como estabilizadas, após a redemocratização que sucedeu a ditadura civil militar. Mas, como em um acelerador de partículas, forças até então intangíveis começaram a ganhar intensidade, atratores de novas dinâmicas sociopolíticas traidoras, golpistas, organizadas à base de corrupção, compromissadas e açuladas pelo neoliberalismo. 
No espetáculo Preto, esses novos atratores são evocados em cenas breves, entrecortadas, como nos monólogos simultâneos entre três atores, cada um referindo uma diferente interpretação sobre os acontecimentos pós-2013, e que culminam com uma imagem icônica: uma mulher negra com um homem negro morto no colo, uma pietá brasileira. Ela diz "quem vai abrir mão pra dividir? E nós vamos ter fôlego pra plantar em cada comunidade, em cada reunião, alguma ação?" (PASSÔ, 2019, p. 62).

Em outro rizoma dessa sequência, ostentando enormes cabeças, desrealização de cada qual em cena, uma sucessão de frases informa as motivações por trás das condutas, apontando para o diálogo surdo, não ouvido, obtuso e repleto de pontos de vista tóxicos e contraditórios, evocação da polaridade ideológica que tomou o país após a operação Lava Jato.

Próximo ao final, Grace Passô novamente toma a palavra como ao início da conferência. Sua voz agora grita, zumbe, se entrecorta entre o sofrimento e a dor, se deixa levar junto às intensidades mais primordiais. Sua memória atual é uma pletora de estados, vividos em duração, e uma potente declaração ressoa:

é como se não desejasse escutar nada que não seja esse fogo de não apagar. Nada que não seja essa minha primavera. Nada que não seja esse meu amor preto, esse meu tesão preto. Esse pensamento preto. Essa concretude preta. Esse Nam myoho rengue kyo, preta. Esse laroye, preta. Esse preta que está na preta. [...] Porque tenho nascido todos os dias e tudo está preto pra mim tudo está preto (PASSÔ, 2019, p. 72) ${ }^{2}$.

Em chave poética, o que aqui temos é uma perspectiva decolonial. Trata-se não apenas de tudo enegrecer, mas sobretudo de livrar-se de uma consciência colonial, através do apelo às forças nascidas em outras longitudes, uma enérgica busca em ser o Outro do Outro. Tal conceito foi forjado por Grada Kilomba para rebater o conhecido emprego de Outro, reivindicado por Simone de Beauvoir em

\footnotetext{
${ }^{2}$ Nam Myoho-rengue-kyo é o título do Sutra de Lótus, cujo original em sânscrito é Saddharma Pundarika, o principal ensino do Buda Shakyamuni. Ele foi traduzido no ano 406 por Kumārajīva recebendo em chinês o nome de Myoho-Renge-Kyo. In Wikipédia: https://pt.wikipedia.org/wiki/Daimoku, acesso em 25/10/2019. Laroyê ou laroiê é palavra de origem Yorubá e não possui uma tradução adequada em língua portuguesa. De forma aproximada, significa "olhai por mim", "me guarde".
} 
relação à mulher: ela é o Outro do homem. O que a pensadora negra portuguesa replicou, ao aplicar o conceito à mulher afrodescendente, foi tomá-la como o avesso do avesso, uma vez que ela é também o Outro da mulher branca frente aos feminismos em curso.

Um novo prolongamento desse movimento surge mais à frente, quando outra atriz negra ocupa o centro do palco e diz que vai dançar um samba "pra vocês". Mas ela não dança, ela não posa, ela se recusa a assumir o lugar de objeto subalterno a que sempre esteve relegada: "eu não vou, eu não quero, eu vou representar o Brasil pra vocês... não, não e não, eu não vou, eu não vou... eu vou é tacar fogo, eu vou fazer o meu caminho" (PASSÔ, 2019, p. 70 e 71), em frases maiúsculas que explicitam não apenas sua indignação como, igualmente, sua consciência em subverter aquele status.

A perspectiva decolonial mais consequente reitera negar quer a modernidade colonialista, implicada na hegemonia branca e masculina, quer, igualmente, a feminista branca, razão pela qual muitas intelectuais afrodescendentes insistem em se manter equidistantes tanto de uma como de outra corrente hegemônica. O cultivo de poderes ancestrais - muitas vezes ironizados como apelos a um "pensamento selvagem" - integra essas estratégias de sobrevivência.

De um ponto de vista hegemônico, a história costuma ser apresentada como a criação global de uma modernidade, como um projeto civilizatório que unificou o planeta em torno dos mais caros ideais do lluminismo. Tal critério de medição de distâncias culturais entre o chamado Ocidente e o resto do mundo foi naturalizado em relação a todas as sociedades, como um percurso universal de desenvolvimento. Apagam-se, com tais expedientes, a história dos genocídios, dos etnocícios, dos desastres ambientais e humanos que marcaram 0 alastramento europeu pelo mundo, perspectiva que o atual modelo econômico neoliberal faz ainda mais perpetuar e aprofundar, através daquilo que é conhecido como "estado de exceção".

Foi o que levou Achile Mbembe a cunhar o termo necropolítica para designar essa devastadora enterprise em escala planetária, especialmente 
quando apoiada em preconceitos, exclusões e emprego do genocídio como arma de ataque contra populações indefesas, vulneráveis ou expatriadas. Segundo ele:

A questão é: qual é, nesses sistemas, a relação entre política e morte que só pode funcionar em um estado de emergência? $\mathrm{Na}$ formulação de Foucault, o biopoder parece funcionar mediante a divisão entre as pessoas que devem viver e as que devem morrer. Operando com base em uma divisão entre os vivos e os mortos, tal poder se define em relação a um campo biológico do qual toma o controle e no qual se inscreve. Esse controle pressupõe a distribuição da espécie humana em grupos, a subdivisão da população em subgrupos e o estabelecimento de uma cesura biológica entre uns e outros. Isso é o que Foucault rotula com o termo (aparentemente familiar) "racismo". (MBEMBE, 2018, p. 17)

Atravessam Preto, portanto, diversas forças ativas e reativas, contrapostas e em permanente desafio, levando a plateia a experimentar momentos paradoxais, inusitados, estribados em cenas, palavras e gestos que desbordam os entendimentos medianos e convencionais.

Se nos acostumamos a entender a narrativa como a sucessão necessária e verossímil entre causas e efeitos, na melhor tradição aristotélica, o espetáculo Preto promove, através de seus estratagemas, golpes e contragolpes poéticos os mais variados, visando deslocar o eixo de entendimento do público. Ele está aberto e promove acontecimentos cênicos, nódulos de apreensão nem sempre concluídos no calor da hora da participação no evento cênico, mas capazes de operarem à distância - temporal e espacialmente. Ou, dito em outros termos, fazendo precipitar na consciência do público estímulos que podem demorar dias para se completarem inteiramente, longe da cena teatral. Esse, talvez, seja seu maior impacto poético.

Ao se deslocar temporalmente daqui para ali, entre lembranças e rememorações, entre fatos pequenos e íntimos e outros abarcando décadas ou séculos, processos sociais complexos e polimorfos, Preto desestabiliza as noções preconcebidas de historicidade. Para uma consciência cartesiana, embora o tempo também seja sentido enquanto duração, sua percepção da história ainda é 
tomada como uma sucessão de experiências sociais, como uma escala de tempos civilizatórios. O espetáculo Preto nos informa de outras possibilidades. Aquela em que a duração, agora vivida como máquina de guerra, ultrapassa a linearidade e se constrói através de novas lógicas discursivas, aptas ao simultâneo, ao sincrético, ao acelerador promovido pelo atual, uma vez que a urgência é um de seus mais proeminentes predicados. É essa sua perspectiva decolonial, ao promover um ato performativo relativo à apreensão histórica da negritude como um motor para novas concepções de futuro.

Recebido em 25/02/2020

Aceito em 03/04/2020

\section{Referências}

DELEUZE, G. Bergsonismo. São Paulo: Ed. 34, 1999.

DELEUZE, G. Conversações. São Paulo: Ed. 34, 2013.

DELEUZE, G. Nietzsche e a filosofia. São Paulo: Ed. n-1, 2018.

MBEMBE, A. Necropolítica. São Paulo: Ed. n-1, 2018.

NIETZSCHE, F. Para além do bem e do mal. São Paulo: Ed. Brasiliense, 1987.

PASSÔ, G.; ABREU, M.; NAIRA, N. Preto. Rio de Janeiro: Cobogó, 2019. 